\title{
Collaboration and Critical Mass among Nascent Companies
}

\author{
Cesar Bandera \\ Assistant Professor of Entrepreneurship \\ Martin Tuchman School of Management \\ New Jersey Institute of Technology \\ bandera@njit.edu
}

\author{
Ellen Thomas \\ Associate Professor of Marketing \\ Martin Tuchman School of Management \\ New Jersey Institute of Technology \\ ellen.thomas@njit.edu
}

\begin{abstract}
The lure of social capital motivates startups to form in clusters with similar companies. However, having social capital is different from exploiting it, and there is conflicting research on the ultimate commercial success of cluster members. This work attempts to disambiguate the relationship between a startup's membership in a cluster and the startup's performance by modeling the availability of social capital separately from its use. Using the longitudinal Kauffman Firm Survey of 4928 companies founded in 2004 and the County Business Patterns from the United States Census Bureau, we compute a measure of relevant social capital available to a startup as the number of companies with the startup's 2-digit NAICS code in the startup's ZIP code, and the startup's use of social capital as collaborations that impact the startup's competitive advantage. We find that collaboration mediates the relationship between cluster density and firm revenue over its first eight years. This work suggests that the administrator of a critical mass of entrepreneurs, such as that of a business cluster or incubator, needs to promote the exploitation of its social capital and not just its accumulation.
\end{abstract}

\section{Introduction: Social Capital and Critical Mass in Business Incubation}

A company's social capital is a measure of its relationships with its ecosystem [1, 2]. Social capital correlates with entrepreneurial success when the startup is in an innovation cluster [3-6], and has been found to be more indicative of entrepreneurial success than intellectual property [7].

Related to social capital is the concept of "critical mass" which denotes a minimum number of nascent firms in a cluster necessary to foster collaborations that promote the success of the firms [4, 8-11].
These collaborations involve on-site and off-site agents for innovation and commercialization, and include investors, business service providers, university and government labs, and other startup tenants in the cluster. Achieving critical mass is a goal of the administrators of innovation clusters and small business incubators $[12,13]$ as is the exchange of tacit knowledge within them [14], but the process of achieving this is anecdotal and literature defines the associated concepts inconsistently [15].

Clusters are geographic concentrations of interrelated companies in a particular field that compete but also cooperate [16]. It has become accepted wisdom in the organization of markets literature that similar businesses will cluster in physical space [16-18] due to the fact that firms benefit from access to resources, specialized staff, venture capital, suppliers, and support services [19]. It has also been found that proximity will stimulate communication and scientific exchange of ideas [20].

While logic supports the above in industries where supply chain costs are substantial (e.g., transporting supplies and finished goods), the fact that we accept as true geographic clusters in hightechnology industries, such as Silicon Valley, is less clear. In this case, we would not expect the extent of social capital and the exchange of tacit knowledge to constrain a firm to a certain geographic location.

However, in their study on the use of information technology in new product development teams, Kawakami, Durmusoglu and Barczak [21] found that although high audiovisual quality teleconferencing is becoming ubiquitous, conversations can still be difficult; emotion and body language are not well conveyed, participants must coordinate actions more precisely than when meeting in person, and by not facilitating low-latency interaction, it can impede important spontaneous discussion. Therefore, understanding the relationship between social capital offered by co-locating geographically, social capital utilization, and firm performance even for high-tech companies is an important research question. 
Stuart and Sorenson's study of the bio-tech industry [18] suggests clustering plays an essential role for entrepreneurs in high-tech industries because social relationships allow them to obtain the resources needed to create a new firm. However they find that although entrepreneurs may prefer to establish new firms in geographic concentrations, the most productive new ventures are not located in regional clusters. They speculate this may be due to the highly competitive environment that exists in geographically concentrated locations. They also speculate that the benefits from clustering may disappear as the geographic reach of firm's social network expands.

Fahey and Prusak point out in their critique of the knowledge management discipline that the second most common error committed by researchers and practitioners is "emphasizing knowledge stock to the detriment of knowledge flow" [22, pg. 266]. The dense ecosystem of a cluster is indicative of the large amount of tacit knowledge therein, but not of its mobility within.

Our findings suggest that clustering and the availability of social capital do not necessarily lead to startup survival. This seems to confirm Stuart and Sorenson's finding that while clusters offer conditions conducive to new venture creation, they do not support their growth. Our study also finds that the availability of social capital does not have a significant relationship with the utilization of social capital. In other words, while clustering can offer numerous benefits, it does not guarantee that firms will actually capitalize on those benefits.

\section{Framework: Social Capital and Success}

We research the relationship between the density of a startup's location, the startup's use of social capital, and startup success (Figure 1). Density is defined as the number of companies in the same geographical area that work in similar markets. Density is thus measured with respect to the startup, and the companies counted include the he startup itself, its regional collaborators, suppliers, service providers, and competitors. For example, the density of software companies could be higher in a technology park than in a residential environment. Density also serves as a proxy for a startup's access to social capital.

We define startup success as revenue, in particular balance sheet items that reward successful opportunity exploitation, i.e., sales revenue, loans, grants, and equity investments. We exclude funding from the founder, friends and family because this often precedes the opportunity exploitation phase and thus cannot be used as a measure of it [23]. Different markets can require different durations for startups to incubate (e.g., pharmaceutical product development takes much more time than mobile app development) and can involve different magnitudes of initial revenue. In an attempt to normalize these differences in the definition of success, we use the number of years that the startup posted revenue instead of the actual dollar amount.

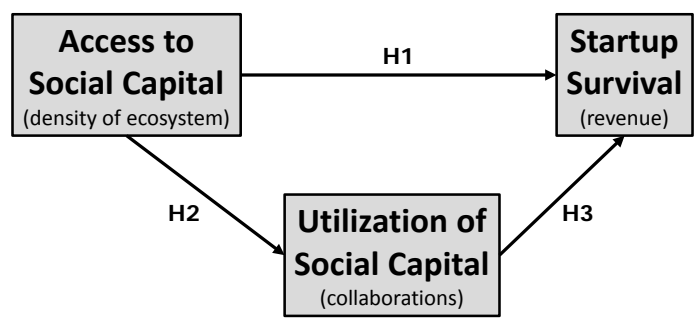

Figure 1. Conceptual framework of the study.

Innovation and entrepreneurship are two different things [24]. To distinguish successful entrepreneurs from successful researchers we exclude from the definition of success those intangible assets commonly associated with opportunity discovery, such as issued patents, even though such accomplishments may subsequently facilitate funding for opportunity exploitation.

Startup density or geographic clustering can lead to performance benefits. In fact Audretsch and Feldman [25] argue that one of the greatest insights in innovation is that geography matters, and that "a long tradition of analyzing the innovative process within the boundaries of the firm and devoid of spatial context has given way to the incorporation of spatial context” (pg. 31).

Theories as to why geography matters include that the concentration of firms improves production efficiency and allows easy access to needed resources, and a highly competitive environment may force firms to be proactive and quickly build needed competencies [26].

Technical knowledge spillover has been found to also positively influence product innovation [17] and entrepreneurs can learn about potential partners and opportunities [27]. In their work on knowledge spillover theory of entrepreneurship, Audretsch and Keilbach [28] investigate entrepreneurship context acknowledging that regions with high knowledge investment experience high knowledge spillover while regions with low investment experience low spillover. They found that a high knowledge context generates new ideas whereby entrepreneurial opportunities are then generated when spillover is exploited. We thus propose: 
Hypothesis 1: Social capital availability is positively associated with startup success.

We measure a startup's use of social capital by counting the collaborations that, in the opinion of the company founder(s), contribute to the startup's market competitiveness. These collaborations are with agents offering complementary resources requisite for commercialization, including intellectual property, production, sourcing, distribution, marketing, and/or financing. This measure distinguishes the use of social capital from merely having access to social capital (i.e., density).

Battisti and McAdam's study of graduate entrepreneurs [29] found that while access to networks of external professionals and advisers was available and valued, they were not relied on. Therefore, it appears that access to social capital may not lead to utilization of it. Shaw found that although social capital can provide new firms with access to a diverse set of resources, firms need to be motivated to access these resources and patterns of utilization can be complex [30]. Moreover, Tornikoski and Newbert found that it was actively networking and receiving outside help that lead to emerging entrepreneurial firms [31].

We therefore propose that the use of social capital is a mediating factor between access to social capital and success:

Hypothesis 2: Social capital availability is positively associated with social capital utilization.

Hypothesis 3: Social capital utilization is positively associated with startup success.

\section{Methods and Data: The Kauffman Firm Survey and Census Data}

This study uses the confidential version of the longitudinal Kauffman Firm Survey (KFS) of 4928 companies founded in 2004 and surveyed annually between 2004 to 2011 [32]. The KFS dataset is augmented by merging it with data from the County Business Patterns (CBP) dataset of the United States Census Bureau that, for every firm in the KFS, specifies the number of companies with the same two-digit North American Industry Classification System (NAICS) code. The CBP augmentation provides this information for every year from 2004 to 2010, and we use it as a measure of the density of the startup's environment.
We measure a startup's use of social capital by whether or not its founder believes that collaborations with other companies, universities, or government labs improved its competitive advantage. The KFS records each class of collaboration in the Boolean variables d2a_compadv_univ_reason,_comp_reason, and _govlab_reason respectively [33] starting in the 2007 survey (Table 1). This data does not describe the nature of the firm's network in detail, such as the topology of strong and weak ties [34], other than classifying collaborative partners into three categories. This network information may not be necessary, however, if one can trust the self-reported claim that collaboration impacted the firm's competitive advantage.

\begin{tabular}{|c|c|c|c|}
\hline Year & University & Company & Gov. Lab \\
\hline 2007 & $7.3 \%$ & $25.5 \%$ & $2.9 \%$ \\
\hline 2008 & $5.9 \%$ & $27.4 \%$ & $2.7 \%$ \\
\hline 2009 & $7.8 \%$ & $30.6 \%$ & $3.4 \%$ \\
\hline 2010 & $8.0 \%$ & $28.8 \%$ & $3.8 \%$ \\
\hline 2011 & $7.8 \%$ & $28.7 \%$ & $3.6 \%$ \\
\hline
\end{tabular}

Table 1. Percentage of startups (excluding nonresponses) that collaborate with other agents.

KFS also provides the income of each startup; the revenue status of the 4928 startups is provided in dataset variable f15_revenue and illustrated in Figure 2 , revealing the traditional exponentially decreasing survival curve of startups ("No Response" includes failed companies).

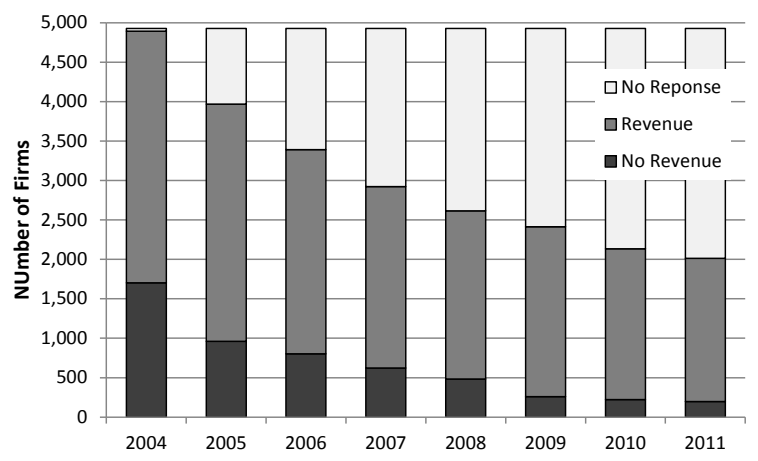

Figure 2. Revenue status of KFS firms.

Table 2 presents descriptive statistics for density, i.e., the number of establishments in the ZIP code of each startup in the KFS with the same two-digit NAICS code as the startup. Density does not vary significantly over time, but does vary significantly spatially. For example, every year at least 75 startups are the only establishments of their two-digit NAICS code in their ZIP code (density=1), and several 
startups are one of over 1000 establishments in the same ZIP code with the same two-digit NAICS code.

We test our hypotheses using structural equation modeling (SEM) because, unlike traditional regression methods, SEM provides information about the consistency of the mediation model, including the simultaneous nature of the indirect and direct effects of collaboration, to the KFS data [35, 36].

\begin{tabular}{|c|c|c|c|c|c|}
\hline Year & $\begin{array}{c}\text { KFS } \\
\text { Startups }\end{array}$ & $\begin{array}{c}\text { Mean } \\
\text { Density }\end{array}$ & Std. Dev. & Min & Max \\
\hline 2004 & 4,830 & 76.65611 & 104.6649 & 1 & 1409 \\
\hline 2005 & 4,257 & 73.9354 & 101.557 & 1 & 1416 \\
\hline 2006 & 3,747 & 76.3811 & 101.872 & 1 & 1421 \\
\hline 2007 & 3,345 & 78.13901 & 101.633 & 1 & 1508 \\
\hline 2008 & 2,931 & 76.70556 & 104.0773 & 1 & 1481 \\
\hline 2009 & 2,659 & 75.72847 & 105.3536 & 1 & 1488 \\
\hline 2010 & 2,342 & 77.06789 & 106.3266 & 1 & 1469 \\
\hline
\end{tabular}

Table 2. Descriptive statistics of startup density

(number of firms in the same ZIP code as the startup and with similar NAICS code).

Density and revenue both fail the normality test with very high skewness and kurtosis. Moreover, the long tail of revenue impeded the structural equation modeling in Stata v14.1 from converging to a solution (e.g., in 2006 the mean revenue was \$835K but the maximum revenue was $\$ 800 \mathrm{M}$ ) and does not account for the fact that some businesses scale more rapidly than others by the market they serve irrespective of social capital utilization. Thus, instead of using revenue directly as a measure of startup success, we instead use the number of years between 2004 and 2011, inclusive, in which the startup posted revenue.

Because our dependent variable spans all the years of the KFS, we likewise measure a startup's social capital utilization over the KFS time frame, specifically as the number of years that startup engaged in collaboration that impacted its competitive advantage. For example, if a startup considered collaboration with companies in 2005, 2006, and 2007 helped its competitive advantage, as did collaboration with a university in 2004, the startup has four collaboration-years of social capital utilization.

\section{Results}

The model was first run three times with 200 bootstrap steps to account for the lack of normality in the data, each time with a different random seed. The results varied so the number of bootstrap steps was raised to 500, at which point the results were consistent with different random seeds. The resulting structural equation model with standardized coefficients and statistical significance is illustrated in Figure 3. The comparative fit index is 1 and the baseline vs. saturated likelihood ratio is 31 with a $\mathrm{p}<0.001$.

The indirect and total effects of density and collaboration-years on the number of years posting revenue are given in Table 3, along with the estimation errors. We observe that the direct effect of density on revenue is inconclusive and in fact slightly negative. However, when collaboration is added as a moderator, the effect of density on revenue is both positive and statistically significant. We thus find that $\mathrm{H} 1$ is unsupported by the model and the KFS data, but $\mathrm{H} 2$ and $\mathrm{H} 3$ are supported.

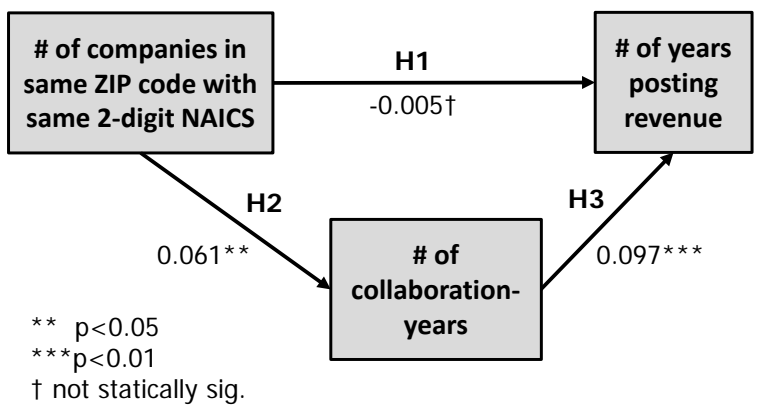

Figure 3. Model with standardized coefficients

\begin{tabular}{|c|l|l|c|c|c|c|}
\cline { 3 - 6 } \multicolumn{2}{c|}{} & $\begin{array}{c}\text { Observed } \\
\text { Coef. }\end{array}$ & $\begin{array}{c}\text { Bootstrap } \\
\text { Std. Err. }\end{array}$ & $\mathrm{z}$ & $\mathrm{P}>|\mathrm{z}|$ & $\begin{array}{c}\text { Normal-based } \\
{[95 \% \text { Conf. Interval }]}\end{array}$ \\
\hline \multirow{3}{*}{ Direct Effects } & Years with Revenue $\leftarrow$ Collaboration-Years & .1344333 & .0269481 & 4.99 & 0.000 & .0816161 .1872505 \\
& Years with Revenue $\leftarrow$ Density & .0001064 & .0004114 & -0.26 & 0.796 & -.0009127 .0006999 \\
\cline { 2 - 7 } & Collaboration-Years $\leftarrow$ Density & .0009041 & .0003807 & 2.37 & 0.018 & .000158 .0016502 \\
\hline Indirect Effects & Years with Revenue $\leftarrow$ Density & .0001215 & .0000581 & 2.09 & 0.037 & $7.59 \mathrm{e}-06.0002355$ \\
\hline \multirow{3}{*}{ Total effects } & Years with Revenue $\leftarrow$ Collaboration-Years & .1344333 & .0269481 & 4.99 & 0.000 & .0816161 .1872505 \\
& Years with Revenue $\leftarrow$ Density & .0000152 & .0004160 & 0.04 & 0.971 & -.0008001 .0008304 \\
\cline { 2 - 7 } & Collaboration-Years $\leftarrow$ Density & .0009041 & .0003807 & 2.37 & 0.018 & .000158 .0016502 \\
\hline
\end{tabular}

Table 3. Model effects and standard errors 


\section{Discussion, Limitations, and Future Work}

The lack of support for $\mathrm{H} 1$ reflects the conflicting findings of Stuart and Sorenson (2003) in that high density environments attract the initial establishment of startups but are not where revenue-generating firms tend to be located. The introduction of collaboration increases model coefficients, which may be an indication that the higher density of relevant companies at a startup's ZIP code leads to higher collaborations that impact its competitive advantage, which subsequently lead to more years with revenue. This also shows that simply being in a higher-density environment does not by itself lead to higher revenue; the startup must make the effort to exploit the available social capital through collaboration. This empirically demonstrates the distinction between knowledge stock and knowledge flow” [22].

This work contributes to incubator best practices by highlighting the importance of social capital sharing to startup success, and by suggesting that cluster administrators promote collaboration within their critical masses. In contrast to building human capital with subject matter experts, which is expensive and difficult to scale, many business incubators have already built the social capital stock desired by their tenants. Our study indicates that incubator administrators should proceed directly to promoting its utilization in a distributed fashion, leveraging the startup density it has amassed.

A limitation of this study is that we did not control for startups whose primary target market are the companies, universities, and government labs with whom they collaborate; consequently, we hypothesize that our model would find a stronger correlation between social capital and company survival for such business-to-business startups than for business-to-consumer startups. Another limitation is that the significance of collaboration on a firm's competitive advantage is subjectively reported. Future work includes exploiting the longitudinal information in the KFS data to conduct a survival analysis of collaboration to obtain further insight into the role of collaboration as a company matures over the eight year period.

\section{References}

1. Baker, R.J., Mind Over Matter: why intellectual capital is the chief source of wealth. 2008: John Wiley \& Sons.
2. Feldman, M. and T.D. Zoller, Dealmakers in Place: Social Capital Connections in Regional Entrepreneurial Economies. Regional Studies, 2012. 46(1): p. 23-37.

3. Davidsson, P. and B. Honig, The role of social and human capital among nascent entrepreneurs. Journal of Business Venturing, 2003. 18(3): p. 301-331.

4. Cooper, S.Y. and J.S. Park, The Impact of 'Incubator' Organizations on Opportunity Recognition and Technology Innovation in New, Entrepreneurial High-technology Ventures. International Small Business Journal, 2008. 26(1): p. 27-56.

5. Ferguson, R. and C. Olofsson, Science Parks and the Development of NTBFs - Location, Survival and Growth. The Journal of Technology Transfer, 2004. 29(1): p. 5-17.

6. Pittaway, L., et al., Networking and innovation: a systematic review of the evidence. International Journal of Management Reviews, 2004. 5(3-4): p. $137-168$.

7. Hayton, J.C., Competing in the new economy: the effect of intellectual capital on corporate entrepreneurship in high-technology new ventures. $R \& D$ Management, 2005. 35(2): $p$. 137-155.

8. Chan, K.F. and T. Lau, Assessing technology incubator programs in the science park: the good, the bad and the ugly. Technovation, 2005. 25(10): p. 1215-1228.

9. Fleming, L. and K. Frenken, The Evolution of Inventor Networks in the Silicon Valley and Boston Regions. Advances in Complex Systems, 2007. 10(1): p. 53-71.

10. O'Neal, T., Evolving a Successful UniversityBased Incubator: Lessons Learned From the UCF Technology Incubator. Engineering Management Journal, 2005. 17(3): p. 11-25.

11. Rogers, E.M., S. Takegami, and J. Yin, Lessons learned about technology transfer. Technovation, 2001. 21(4): p. 253-261.

12. Colbert, C.A., Dinah; Wolfe, Chuck; Lapan, Karl, Best Practices in Action - Guidelines for Implementing First-Class Business Incubation Programs. Revised 2nd Edition ed. 2010: National Business Incubator Association.

13. Cooper, C.E., S.A. Hamel, and S.L. Connaughton, Motivations and obstacles to networking in a university business incubator. The Journal of Technology Transfer, 2012. 37(4): p. 433-453.

14. Bembenek, B. and T. Piecuch. Knowledge Management in Industry Clusters As an 
Indication of Entrepreneurship. in $C B U$ International Conference Proceedings. 2014.

15. Shane, S. and S. Venkataraman, The promise of entrepreneurship as a field of research. Academy of management review, 2000. 25(1): p. 217-226.

16. Porter, M.E., Location, competition, and economic development: Local clusters in a global economy. Economic development quarterly, 2000. 14(1): p. 15-34.

17. Gilbert, B.A., P.P. McDougall, and D.B. Audretsch, Clusters, knowledge spillovers and new venture performance: An empirical examination. Journal of business venturing, 2008. 23(4): p. 405-422.

18. Stuart, T. and O. Sorenson, The geography of opportunity: spatial heterogeneity in founding rates and the performance of biotechnology firms. Research policy, 2003. 32(2): p. 229-253.

19. Saxenian, A., Inside-Out: Regional Networks and Industrial Adaptation in Silicon Valley and Route 128. Cityscape, 1996. 2(2): p. 41-60.

20. Allen, T., O. Raz, and P. Gloor, Does Geographic Clustering Still Benefit High Tech New Ventures? The Case of the Cambridge/Boston Biotech Cluster. 2009, MIT ESD-WP-2009-01 working paper.

21. Kawakami, T., S.S. Durmuşoğlu, and G. Barczak, Factors influencing information technology usage for new product development: The case of Japanese companies. Journal of Product Innovation Management, 2011. 28(6): p. 833-847.

22. Fahey, L. and L. Prusak, The eleven deadliest sins of knowledge management. California management review, 1998. 40(3): p. 265-276.

23. Bygrave, W. and A. Zacharakis, Entrepreneurship. 3rd ed. 2014: John Wiley \& Sons, Inc.

24. Rosenbusch, N., J. Brinckmann, and A. Bausch, Is innovation always beneficial? A meta-analysis of the relationship between innovation and performance in SMEs. Journal of Business Venturing, 2011. 26(4): p. 441-457.

25. Audretsch, D.B. and M.P. Feldman, Knowledge spillovers and the geography of innovation. Handbook of regional and urban economics, 2004. 4: p. 2713-2739.

26. Porter, M.E. and M.P. Porter, Location, Clusters, and the" New" Microeconomics of Competition. Business Economics, 1998: p. 7-13.

27. Al-Laham, A. and V. Souitaris, Network embeddedness and new-venture internationalization: Analyzing international linkages in the German biotech industry. Journal of Business Venturing, 2008. 23(5): p. 567-586.

28. Audretsch, D.B. and M. Keilbach, The theory of knowledge spillover entrepreneurship. Journal of Management Studies, 2007. 44(7): p. 1242-1254.

29. Battisti, M. and M. McAdam, Challenges of social capital development in the university science incubator The case of the graduate entrepreneur. The International Journal of Entrepreneurship and Innovation, 2012. 13(4): p. 261-276.

30. Shaw, E., Small firm networking an insight into contents and motivating factors. International Small Business Journal, 2006. 24(1): p. 5-29.

31. Tornikoski, E.T. and S.L. Newbert, Exploring the determinants of organizational emergence: A legitimacy perspective. Journal of Business Venturing, 2007. 22(2): p. 311-335.

32. Robb, A. and J. Farhat, An Overview of the Kauffman Firm Survey: Results from 2011 Business Activities. 2013, Ewing Marion Kauffman Foundation.

33. Farhat, J.B. and A. Robb, Applied Survey Data Analysis Using Stata: The Kauffman Firm Survey Data. Available at SSRN 2477217, 2014.

34. Pirolo, L. and M. Presutti, The Impact of Social Capital on the Start-ups' Performance Growth. Journal of Small Business Management, 2010. 48(2): p. 197-227.

35. Hooper, D., J. Coughlan, and M. Mullen, Structural equation modelling: Guidelines for determining model fit. Articles, 2008: p. 2.

36. Gunzler, D., et al., Introduction to mediation analysis with structural equation modeling. Shanghai Archives of Psychiatry, 2013. 25(6): p. 390-394. 